\title{
OBSERVAÇÃO DA RELAÇÃO MÃE-BEBÊ NOS PRIMEIROS MESES DE VIDA
}

\author{
Juliana Carneiro de Souza \\ Moisés Fernandes Lemos \\ (Universidade Federal de Goiás, Regional Catalão)
}

\begin{abstract}
Resumo
O presente trabalho teve por objetivo analisar a relação mãe-bebê nos primeiros meses de vida, verificando o vínculo estabelecido e as reações emocionais da dupla. O método utilizado foi o psicanalítico, mais especificamente o método de observação de bebês proposto por Esther Bick (1948). Quanto aos procedimentos de coleta de dados, a pesquisa se delineou como estudo de caso, sendo a amostra composta por uma unidade caso, escolhida intencionalmente e observada durante dois meses. As conclusões evidenciaram a presença do vínculo mãe-bebê e a preocupação materna neste período inicial de vida, uma vez que a mãe se mostrou interessada e adaptada à realidade da criança, assim foi possível desenvolver os objetivos do estudo, respondendo ao problema de pesquisa.
\end{abstract}

Palavras-chave: Relação mãe-bebê; método Esther Bick; Psicanálise.

\section{Abstract}

\section{Observation of the Mother-Baby Relationship in the First Months of Life}

The present study aimed to analyze the mother-baby relationship in the first months of life, verifying the established bond and the emotional reactions of the pair. The method used was the psychoanalytic, more specifically the method of observation of babies proposed by Esther Bick (1948). As for the data collection procedures, the study was delineated as a case study, the sample being composed of a case unit, chosen intentionally and observed for two months. The conclusions evidenced the presence of the mother-baby bond and the maternal concern in this initial period of life, once the mother was interested and adapted to the reality of the child, thus it was possible to answer the proposed research problem and the objectives were reached.

Key-words: Mother-baby relationship; Bick Method; psychoanalysis. 


\section{Introdução}

A relação mãe-bebê é um assunto bastante discutido na área da Psicanálise, devido à importância deste vínculo, principalmente no início do desenvolvimento emocional do ser humano. A mãe é, nos primeiros meses de vida, o elemento central do universo social e afetivo do bebê; aquela com quem estabelecerá uma vinculação bastante forte, colaborando também na constituição de sua estrutura psíquica. Segundo o psicanalista e pediatra inglês Donald Winnicott (1896 1971), essa relação causa um impacto importante na vida inteira de uma pessoa; ele cita que é provável que a capacidade de ser feliz na vida, dependa de um tempo e de uma pessoa: o primeiro ano de vida e a mãe. A função materna que será trabalhada ao longo do texto, tomada em seu sentido genérico, tanto pode ser exercida pela mãe propriamente dita, quanto por outra pessoa que exerça tal função junto à criança (Zimerman, 1999).

A figura da mãe é destacada por ser vista como a que atende às necessidades fisiológicas do bebê e dá o suporte necessário para que as capacidades inatas se desenvolvam. Na concepção de Freud (1915/2006), em seu livro Instintos e suas vicissitudes, esse apego ou vinculação à mãe está associado a ser ela a responsável por essa redução de tensões fisiológicas como fome, sede, conforto e dor. Visto que é nos primeiros anos de vida que a criança é totalmente dependente da mãe para suprir suas necessidades de sobrevivência, a mãe passa a ser um fator externo determinante para o desenvolvimento do bebê, estando a mesma ligada à qualidade das influências pelas quais a criança poderá passar.

Há outros autores que reforçam que a ligação primária entre a dupla vai além da redução de necessidades fisiológicas, destacando que o forte vínculo do bebê com a figura materna, estabelecido no primeiro ano de vida, tem um papel fundamental no desenvolvimento e estruturação do psiquismo da criança e na formação da personalidade do adulto. Dentre eles, cabe destacar: Bowlby (1988/2002), Klein (1978), Spitz (1945/1965) e Winnicott (1988).

Bowlby (1988/2002) interessou-se por estudar os efeitos da separação da criança pequena de sua mãe, para ele, a criança cria um modelo representacional interno de si mesma, dependendo de como foi cuidada, e em sua vida esse modelo permite que a mesma seja capaz de se ajudar e de crer que pode ser ajudada em caso de dificuldades. O fato de a criança confiar em si própria e a relação de segurança criada com seus cuidadores irão ajudá-la a separarse dos pais gradativamente, a tornar-se 
independente, sendo possível explorar a sua liberdade. $\mathrm{O}$ autor menciona que “[...] adolescentes e adultos saudáveis, felizes e autoconfiantes são produtos de lares estáveis, nos quais tanto o pai quanto a mãe despendem grande parte do tempo e muito de sua atenção com as crianças" (Bowlby, 1989/2002, p. 18).

Spitz (1945/1965), em um trabalho no orfanato, observou que os bebês que eram alimentados e vestidos, mas não recebiam afeto apresentavam a síndrome denominada por ele de hospitalismo; notou que esses bebês tinham dificuldades no desenvolvimento físico, faltava-lhes apetite, não ganhavam peso e, com o tempo, perdiam o interesse em se relacionar, o que levava a maioria deles ao óbito.

Conforme afirma Borsa (2007), o vínculo mãe-bebê é construído através da empatia e o cuidar do bebê, assim, não só as necessidades físicas serão atendidas, mas as emocionais também, pois há um investimento emocional dos pais que influencia fortemente o bebê.

Para Winnicott (1983), é especialmente no início da vida que as mães são imprescindíveis, pois carregam consigo a tarefa de proteger a continuidade de ser do bebê:

Quando o ambiente não é satisfatoriamente bom, a continuidade do 'ser' pode ser interrompida, resultando no enfraquecimento do ego e na não existência psíquica do bebê. A criança está presente enquanto um corpo orgânico, que até reage aos estímulos do meio, mas não existe enquanto ser capaz de estar e criar no mundo. (Winnicott, 1983, p.128).

O mencionado autor parte do pressuposto de que o desenvolvimento do bebê depende de um ambiente facilitador, sendo este ambiente, caracterizado por uma mãe suficientemente boa, pois o atende na medida exata das suas necessidades; daí a relevância dos sentimentos da mãe durante o período da gestação e após o nascimento. Considera que a mãe desenvolve nos primeiros meses um estado psicológico denominado "preocupação materna primária", no qual o "enlouquecimento materno" é importante para que o bebê seja sustentado e manipulado de acordo com as suas próprias necessidades. Nas palavras do autor,

A mãe desenvolve o estado que chamei 'preocupação materna primária', a mãe se identifica com o bebê e fornece um setting no qual a constituição do bebê pode se mostrar, suas tendências de desenvolvimento podem começar a se revelar e o bebê pode experimentar um movimento espontâneo e dominar 
as sensações apropriadas a esta fase da vida (Winnicott, 1956/1993, p. 495).

Apesar de ser um período normal e necessário, em que a mãe renuncia certos interesses pessoais, ela precisa estar saudável para entrar nesse estado e recuperar-se dele. Tudo isso é crucial para o desenvolvimento do bebê, pois proporcionará um contexto para que a constituição da criança comece a se manifestar.

\subsection{A Constituição do Sujeito Segundo a Psicanálise}

A construção psíquica é um processo pelo qual o bebê precisa passar para que venha a se estabelecer como sujeito. De acordo com a Psicanálise, o sujeito se organiza por meio da relação com o outro e das experiências que ele vivencia. Logo em seus primeiros meses, quando é amparado por um adulto, o bebê se identifica com ele e se reconhece como humano a partir da imagem de seu cuidador. Este fará com que a criança sobreviva por meio do preenchimento de funções, como alimentação, higiene, deslocamento, além de dar significação a todas essas necessidades para que se inscreva um sujeito neste bebê. É durante esses primeiros cuidados que transmitirá a cultura, a linguagem e a história já presentes no mundo antes do nascimento da criança. Ressaltando que o sujeito, para a Psicanálise, é aquele que se constitui na relação com o Outro por meio da linguagem.

Apesar da concordância entre autores como Freud (1905/2006), Dolto e Násio (1991), Klein (1978) e Winnicott (1987) sobre a importância do outro nesse processo, há diferentes teorias de como se dá a constituição do psiquismo.

Para Freud (2006), o sujeito é aquele que está assujeitado à exigência de satisfação da pulsão e a sua constituição se dará por meio do desenvolvimento psicossexual na infância. $O$ corpo da criança é tomado por pulsões parciais autoeróticas que têm como referência um órgão ou uma zona erógena, são pulsões sexuais fragmentadas e independentes entre si no que diz respeito à busca pela satisfação; a obtenção de prazer é encontrada no próprio corpo e não em um objeto externo. A mãe, ao amamentar o filho, é capaz de instalar nele o prazer:

A mãe amamenta o filho, suprindo sua fome e ao mesmo tempo instalando nele o prazer. Isso significa pôr em movimento seus orifícios pulsionais, ou seja, provocar a erotização do corpo numa antecipação de que aí se trata de um sujeito. Ela oportuniza ao bebê o início da constituição psíquica. Essa 
constituição só é possivel quando o infans passa a investir em outro objeto que não só o seio materno, elegendo uma parte de seu corpo ou qualquer outra coisa que the proporcione prazer. (Freud,1905/2006, p.172).

Na teoria de Freud, a fase que dá início à organização sexual infantil é a fase oral, em que a região do corpo que proporciona maior prazer à criança é a mucosa da boca, acontece de 0 a 1 ano; é a forma da criança entrar em contato com o mundo e o principal objeto de desejo é o seio da mãe. Esse ato provoca o prazer pela repetição, esvaziando a pulsão, e ao mesmo tempo oportuniza ao bebê o início da constituição psíquica. De 2 a 4 anos é a fase anal em que a criança passa a adquirir o controle dos esfíncteres e a zona de maior satisfação é a região do ânus, nesta etapa ela passa a ter noção de higiene. De 4 a 6 anos é a fase fálica, a criança se volta para a região genital, há o complexo de castração (no complexo de castração a criança imagina que tanto os meninos quanto as meninas possuem pênis, então a menina tem medo de perder o pênis) e o complexo de Édipo. No complexo de Édipo do menino, o sujeito mantém a sua mãe como objeto de amor, já que ela satisfaz todas as necessidades dele. Por outro lado, o pai surge como um "entrave" nessa relação já que há um interesse desse pai para com a mãe e vice-versa. Ele tem o pai como rival e quer se ver livre dele, tomando o seu lugar. Na menina, ela descobre a existência do pênis nos meninos, dando conta de que não possui tal órgão e acredita ser a única criança nesta situação, frente a esta decepção ela responsabiliza e culpa sua mãe.

De 6 a 11 anos é a fase de latência, que tem por característica um adormecimento da pulsão sexual ou um deslocamento da libido da sexualidade para atividades socialmente aceitas (ex: brincar); e, por fim, a fase genital, a partir dos 11 anos, quando há uma retomada dos impulsos sexuais e o adolescente passa a buscar um objeto de amor.

Klein (1935/1978) teoriza que a relação arcaica do bebê com a mãe é o principal elemento de constituição do psiquismo. Segundo a autora, existem duas formas na constituição da subjetividade do bebê ou duas posições: $a$ ) posição esquizoparanóide e b) posição depressiva. A posição esquizo-paranóide se inicia no nascimento indo até os seis meses; o seio da mãe é a primeira relação do bebê. Ele é o objeto primordial, sendo, simbolicamente, dividido em seio bom (amado) e seio mau (odiado). O bebê percebe o seio como "bom" porque o amamenta e como "mau" porque falta. Quando a mãe se ausenta o bebê inaugura o processo de clivagem em sua subjetividade como defesa. Nessa fase, 
instala-se no bebê uma angústia persecutória, pois acredita que o seio mal é perseguidor e destrói o seio bom, então a meta da criança nessa fase é possuir o objeto bom e introjetá-lo e também de projetar o objeto mau para fora e assim evitar os impulsos destrutivos.

A posição depressiva se inicia aos seis meses, sendo nessa fase que a criança inaugura o sentimento de ambivalência pela mãe e teme que seus próprios impulsos destrutivos possam destruir o objeto amado e odiado, desenvolvendo sentimento de culpa e luto.

Conforme Chiadi (2015), citando Klein:

Na teoria de Klein, a ansiedade depressiva é a fonte da verdadeira capacidade de amar, a qual é inicialmente expressa através de ansiedade pela destruição do outro, culpa, remorso, desejo de reparar o dano feito, responsabilidade em preservar o outro e tristeza relacionada com a possibilidade de perdê-lo. A capacidade de identificação com o outro na posição depressiva tem como consequência o amor. Assim, a criança se torna capaz. de encontrar outros objetos de interesse e o seu amor é dirigido também para outras pessoas e coisas. (Chiadi, 2015, p.1)
O bebê, que na ansiedade depressiva temia a destruição do seu objeto amado por perseguidores, preocupando-se somente com o bem-estar do ego, mais adiante vai temer que essa sua agressão possa destruir o objeto ambivalente amado e odiado, importando-se com o bem-estar do outro. Assim, para a autora, é dessa forma que o bebê vai constituir seu psiquismo.

A relação maternal é um tema central nas obras de Winnicott (1956/1987), o autor parte do pressuposto de que este vínculo entre mãe-bebê é a base fundamental para o desenvolvimento saudável das capacidades inatas do indivíduo e a constituição do psiquismo. Leva em conta o ambiente, representado geralmente pela mãe suficiente boa. Para o estabelecimento do ego é necessário um suficiente "continuar a ser" do bebê, não interrompido por reações à intrusão, pois é a mãe quem vai proporcionar esse "continuar a ser" suficiente a partir do momento em que se encontra no estado psicológico denominado por ele como “preocupação materna primária”, que é uma condição organizada na qual há um estado de completa devoção ao bebê.

Dolto e Násio (1991) afirmam que o bebê sozinho não tem meios de subjetivação, logo, é na relação com o outro que ele irá se humanizar. A relação maternal é a primeira e principal segurança narcísica do bebê; é através dela que há a mediação 
de percepções. Tais percepções dão as condições necessárias para o bebê vir a ser falante e receptivo, à espera de trocas vocais ou gestuais. Caso o bebê não encontre resposta às suas solicitações, na ausência da mãe, ocorrerá a perda dessa mediação das experiências que lhe dão sentido, promovendo uma descontinuidade no "co-ser" da criança, conceito equivalente ao "vir-a-ser" do bebê na teoria winnicotiana. A autora, diferentemente de outros teóricos, valoriza, além da relação diádica com a mãe, ou com quem exerce a função materna, uma relação tríade, incluindo o pai no contexto.

\subsection{Sobre o Método Bick}

O Método Bick de observação foi desenvolvido pela psicanalista inglesa Esther Bick, em 1948, na Clínica em Tavistock, em Londres. Foi originalmente proposto com o intuito de auxiliar a formação de psicoterapeutas, devido à oportunidade de uma experiência prática com bebês, reconhecendo o benefício que esse método pode trazer à formação clínica. Como no consultório, o observador é receptivo, estabelece o holding e a sensibilidade para comunicação.

Tal método visa prover uma experiência prática com bebê, permitindo acompanhar o seu desenvolvimento e sua relação com seus familiares, principalmente com a mãe. A observação começa no dia do nascimento do bebê indo até o término do segundo ano de vida e se consiste em:

[...] o observador fazer uma visita a casa da família com duração de uma hora e frequência semanal no primeiro ano e quinzenal no segundo ano. Anotar com o maior número de detalhes que for possível o que observar e depois relatar no grupo de supervisão cujo objetivo é descrever o desenvolvimento da relação entre o bebê e o meio ambiente. Além disso, o observador deve tentar compreender os aspectos inconscientes do comportamento e padrões de comunicação, bem como entender os sentimentos despertados durante esta observação nele próprio (Kompinsky, 2000, p. 13).

A experiência é constituída em três tempos: o momento da observação, o momento do relato da observação e o momento do relato da observação na supervisão. É recomendável que nos relatos sejam incluídos todos os afetos experimentados pelo observador para que sejam trabalhados na supervisão, evitando que interfiram em uma observação que deve ter caráter neutro. O observador é orientado a adotar determinada postura durante as 
visitas, sobretudo deverá ter uma postura empática, porém não intrusiva:

O observador é orientado a participar da experiência, despindo-se, tanto quanto possível, dos seus hábitos terapêuticos e teorias que embasam o seu dia-a-dia clínico, para poder, então, tão somente observar. A palavra de ordem presente na descrição do método e seus achados por Bick é que partimos do não-saber: eu não sei e não procuro nenhuma conclusão. [...] é relevante uma atitude de espera, tolerância e paciência frente ao desconhecido e ao "não saber". Significa deixar-se penetrar por mensagens não compreendidas, tolerar esta não-compreensão, suportar viver na falta de um sentido, aguardando que ele surja. Além disso, o observador deve ser discreto, atento, receptivo, delicado e não crítico, para depois relatar suas observações nos mínimos detalhes. Não deve aconselhar, interpretar, interferir. (OliveiraMenegotto, Menezes, Caron \& Lopes, 2006, p. 80).

Desse modo, o observador, com postura reflexiva, tem a oportunidade de estar aberto à investigação do novo, despido de intervenções prontas, possibilitando novos saberes e o entendimento de cada relação mãe-bebê em sua singularidade, além de desenvolver a atenção qualificada no momento da observação. O observador não está ali para quantificar, normatizar, comparar, validar ou informar a observação e, sim, para ter acesso a momentos únicos, como a experiência da relação mãe-bebê e suas implicações no desenvolvimento.

A família do bebê, após estabelecer o vínculo com o observador, beneficia-se com as visitas, pois será um momento no qual todos terão a possibilidade de se aliviarem e descarregarem sentimentos, angústias, ansiedades, emoções com o observador, que tem como característica ser empático e isento de julgamentos. Assim como a família, o observador também se favorece com a prática; Bick (1964/1987) considerava a observação de bebê uma excelente oportunidade para psicoterapeutas observarem o desenvolvimento do bebê, desde o nascimento, na casa, na sua relação com a família e descobrirem como se originam e se desenvolvem tais relações ao longo dos dois primeiros anos de vida do bebê. À medida que o observador passa a ter maior confiança no valor de sua presença na casa do bebê e a perceber a importância que a família lhe empresta, dá conta de que há uma troca nessa relação (Farias \& Tucherman, 1988).

Durante as visitas semanais com duração de uma hora há pontos importantes 
a serem observados. Kompinsky (2000) destaca que os aspectos principais considerados durante a observação são: a relação mãe-bebê (antes e depois do parto); o banho, a higiene e a troca de fraldas; a alimentação, a amamentação; a maneira como o bebê é tranquilizado (em situação de dor, fome, desconforto, angustia); o sono; o choro; o brincar; a "conversa"; o sorriso; as solicitações e a participação de cada membro da família.

Outro escritor sobre observação de bebês é Manuel Pérez Sanchez, discípulo de Esther Bick, psicanalista e um dos principais difusores do método de observação psicanalítica mãe-bebê. Em 1983 publicou o livro: Observacion de Bebés: relaciones emocionales em el primer año de vida; em sua obra há uma noção do todo de sua observação de um ano. Supervisionado por Bick, ele discute vários aspectos do relacionamento da dupla que foram aparecendo ao longo das observações da relação mãe bebê. Sanchez tinha o objetivo de divulgar o método de observação e de reconhecer as emoções dos primeiros estágios da vida, para conseguir alguma experiência das etapas primárias e na evolução do psiquismo.

Perez-Sanchez (1983) sugere que o observador deve se colocar no fundo, não mostrar grande entusiasmo e não chamar atenção sobre si mesmo. O melhor é não perguntar, apenas esperar; não tomar nenhuma iniciativa porque, fazendo-o, está assumindo um papel. E caso dirijam alguma pergunta no decorrer da observação, deve tentar responder com naturalidade, o mais brevemente possível, a fim de que a resposta não interfira de alguma forma ou prejudique a observação. A sua resposta, porém, deve mostrar que considera os sentimentos do outro.

A partir do método de pesquisa de Esther Bick e das observações que são propostas, é possível atentar para como o vínculo entre a mãe e seu bebê vai se constituindo desde as primeiras horas de vida do recém-nascido. Sendo assim, o presente trabalho se propõe a responder à seguinte questão norteadora: como a relação mãe-bebê é construída nos primeiros meses de vida do bebê?

$$
\mathrm{O} \text { presente estudo mostra-se }
$$
relevante, uma vez que parte do pressuposto de que a ausência da relação materna causa prejuízos no desenvolvimento infantil, indicando que as consequências são de ordem física, intelectual e social, influenciando no aparecimento de enfermidades. Contudo, as consequências emocionais ou psicológicas são menos investigadas. Do ponto de vista social, a pesquisa representa uma oportunidade de conhecer melhor a relação mãe-bebê nos primeiros meses de vida, podendo contribuir para o desenvolvimento da maternagem de uma mãe de primeira 
gestação e prevenir problemas na constituição do bebê como sujeito, embora não seja possível dimensioná-los durante o estudo. Além disso, a experiência foi uma oportunidade de observar o desenvolvimento de um bebê desde o nascimento, no ambiente do lar e sua relação com a família, acompanhando como se originam e desenvolvem tais relações.

$\mathrm{O}$ presente trabalho objetivou investigar como a relação mãe-bebê é construída nos primeiros meses de vida do bebê. A pesquisa objetivou ainda: a) analisar a participação da mãe na construção do psiquismo do bebê nos primeiros meses de vida; b) apontar possíveis prejuízos de uma relação mãebebê mal estabelecida; c) apresentar a opinião de autores psicanalíticos sobre a importância dessa relação; e d) destacar a importância do Método Esther Bick.

\section{Método}

Trata-se de uma pesquisa qualitativa, descritiva, quando considerados seus objetivos; o trabalho é delineado como estudo de caso, quando classificado a partir dos procedimentos de coleta de dados (Gil, 2008). A pesquisa qualitativa abrange um campo transdisciplinar, englobando as ciências humanas e sociais. Engloba diferentes correntes de pesquisa com pressupostos contrários ao modelo experimental, adotando técnicas de pesquisa distintas deste. Ela envolve métodos e técnicas de investigação que abarcam a sua especificidade para o estudo dos fenômenos humanos e sociais (Chizzotti, 2005).

Reconhecendo a especificidade das ciências humanas e sociais conduz-se à elaboração de um método que admita tratar da subjetividade e da singularidade dos fenômenos. Mediante esses pressupostos para a pesquisa qualitativa, a representatividade dos dados “[...] está relacionada à sua capacidade de possibilitar a compreensão do significado e a 'descrição densa' dos fenômenos estudados em seus contextos e não à sua expressividade numérica" (Goldenberg, 2003, p. 50).

Não obstante, o estudo de caso caracteriza-se como uma investigação profunda de um objeto, de maneira a permitir amplo e detalhado conhecimento sobre o mesmo, o que seria praticamente impossível através de outros métodos de investigação, conforme afirmam Goode e Hatt (1973). Os autores caracterizam o estudo de caso como um meio de organizar dados e reunir informações, tão numerosas e detalhadas quanto possível, a respeito do objeto de estudo de maneira a preservar seu caráter unitário. A totalidade do objeto pode ser preservada através da amplitude e verticalidade dos dados, por meio dos diferentes níveis de análise, da formação de 
índices e tipos de dados, bem como da interação entre os dados observados e a dimensão temporal em que se dá o fenômeno.

Para o desenvolvimento do estudo foi escolhida uma participante a ser observada após seu primeiro parto. Ela é casada, possui 22 anos, residente na cidade de Catalão-GO, estudante do sétimo período de Direito. A escolha da participante foi intencional. No desenvolvimento do presente trabalho a participante foi denominada Maria.

Foram realizadas oito observações, no período de dois meses, na residência da participante em horários previamente definidos. Não foram presenciados muitos momentos de dificuldades por parte da mãe, pelo fato das visitas serem agendadas em horários de tranquilidade, que possibilitava um clima favorável. As observações tiveram duração de uma hora e foram realizadas em diferentes oportunidades, preferencialmente em situações em que o bebê estivesse acordado. O primeiro contato da observadora com Maria se deu quando ela estava grávida de oito meses e o objetivo foi apresentar a proposta de observação da dupla (mãe-bebê). A observadora introduziu a questão dizendo que gostaria de ter alguma experiência direta com bebês recém-nascidos e conhecer de perto a interação mãe-bebê como parte de sua formação acadêmica e, para isso, gostaria de permanecer junto da mãe e de seu bebê semanalmente, por uma hora durante dois meses, deixando claro que não teria outras atribuições (aconselhar, ensinar, orientar, etc.).

As sessões de observação foram registradas em diário de campo e os dados levantados foram avaliados segundo a teoria psicanalítica, ou seja, os dados foram submetidos a uma análise qualitativa em conformidade com a psicanálise, mais especificamente, os achados de Bick.

No que tange aos aspectos éticos, observou-se as recomendações da Resolução 510/2016, combinada com os dizeres da Resolução 466/2012, ambas publicadas pelo Conselho Nacional de Saúde, as quais estabelecem as normas para a realização de pesquisas com seres humanos. 


\section{Apresentação dos Resultados}

Quadro 1 - Demonstrativos de observações da relação mãe-bebê

\begin{tabular}{|c|c|c|c|}
\hline Observação & Período/dias & $\begin{array}{l}\text { Situações } \\
\text { Observadas }\end{array}$ & $\begin{array}{c}\begin{array}{c}\text { Síntese dos } \\
\text { Relatos }\end{array} \\
\end{array}$ \\
\hline Primeira & Uma semana & $\begin{array}{l}\text { Relatos sobre o } \\
\text { parto }^{1}\end{array}$ & $\begin{array}{l}\text { Maria relatou sobre como descobriu a } \\
\text { gravidez, sobre as expectativas dela e do } \\
\text { marido durante a gestação, em saber } \\
\text { como seria o bebê fisicamente e em } \\
\text { relação ao sexo. Descreveu o momento } \\
\text { do parto, desde quando chegou ao } \\
\text { hospital ao momento em que pegou sua } \\
\text { filha e a ouviu pela primeira vez. As } \\
\text { dificuldades desses primeiros dias como } \\
\text { mãe também foram expostas. }\end{array}$ \\
\hline Segunda & Duas semanas & $\begin{array}{l}\text { Banho e troca de } \\
\text { fraldas }\end{array}$ & $\begin{array}{l}\text { Nesta visita ela relatou como se adaptou } \\
\text { rápido no sentido de se abdicar de muitos } \\
\text { afazeres e saídas em prol da filha. Foi } \\
\text { observado o modo como a mãe foi dando } \\
\text { sentido às expressões e choros da filha e } \\
\text { a maneira como conversava, a fim de } \\
\text { descobrir o que estava a incomodando, } \\
\text { principalmente na hora do banho e da } \\
\text { troca de fraldas que era o momento em } \\
\text { que sua filha tinha mais expressões. }\end{array}$ \\
\hline Terceira & Três semanas & Banho & $\begin{array}{l}\text { Maria relatou na observação que notava } \\
\text { que a relação com a filha estava se } \\
\text { construindo quando ela queria somente o } \\
\text { colo dela e quando todo dia às seis horas } \\
\text { da manhã sua filha chorava para ir buscá- } \\
\text { la no quartinho e levar para o quarto da } \\
\text { mãe ou quando sua filha chorava } \\
\text { procurando seu peito e não mamava, } \\
\text { apenas encostava o rosto no peito para } \\
\text { dormir. Durante o banho demonstrou que } \\
\text { já sabia o que fazer para a filha gostar } \\
\text { (balançar ela na água) e o que ela não } \\
\text { gostava (banheira cheia e água morna). }\end{array}$ \\
\hline Quarta & Quatro semanas & $\begin{array}{l}\text { Amamentação e } \\
\text { troca de fraldas }\end{array}$ & $\begin{array}{l}\text { Foi observado como Maria estava } \\
\text { preocupada com as feridas da sua filha, } \\
\text { seguindo todos os procedimentos } \\
\text { necessários para amenizar a dor que as } \\
\text { assaduras estavam provocando. Na hora } \\
\text { da amamentação olhava a filha mamar e } \\
\text { conversava com ela. }\end{array}$ \\
\hline
\end{tabular}

10 médico obstetra não permitiu duas pessoas na sala de parto. Então, optou-se pela presença do esposo. 


\begin{tabular}{|c|c|c|c|}
\hline Quinta & Cinco semanas & $\begin{array}{l}\text { Interação da } \\
\text { bebê com a } \\
\text { família }\end{array}$ & $\begin{array}{l}\text { A quinta observação se centrou em } \\
\text { evidenciar observar como a família } \\
\text { interagia com a bebê e vice-versa, já que } \\
\text { foi em um horário em que todos estavam } \\
\text { reunidos para almoçar. Estavam } \\
\text { presentes a mãe, o pai, o avô e a tia da } \\
\text { criança, todos no quarto dela vendo a } \\
\text { mãe trocar a fralda e dar banho na } \\
\text { mesma. Durante esse momento foi } \\
\text { possível observar o quanto a mãe já está } \\
\text { segura em relação a sua filha e do que era } \\
\text { melhor ou não para ela, visto que todos } \\
\text { queriam dar opinião sobre como ela } \\
\text { deveria dar banho ou qual o jeito melhor, } \\
\text { mas ela seguiu fazendo como estava } \\
\text { acostumada alegando que já conhece } \\
\text { bem o que a filha gosta. }\end{array}$ \\
\hline Sexta & Seis semanas & $\begin{array}{l}\text { Amamentação e } \\
\text { troca de fralda }\end{array}$ & $\begin{array}{l}\text { A sexta observação começou no } \\
\text { momento da amamentação, a mãe estava } \\
\text { encantada com o quanto sua filha estava } \\
\text { cada dia mais esperta e contou dos } \\
\text { gritinhos que ela dava quando } \\
\text { conversava com ela, como se estivesse } \\
\text { querendo responder à mãe. Trocou a } \\
\text { fralda da sua filha após ver que ela estava } \\
\text { ficando vermelha e fazendo sinais com a } \\
\text { boca, passando maisena e pomada para } \\
\text { ela não dar assaduras, disse que notava } \\
\text { que toda vez que ela queria fazer cocô } \\
\text { usava essa expressão. }\end{array}$ \\
\hline Sétima & Sete semanas & $\begin{array}{l}\text { Interação com a } \\
\text { mãe }\end{array}$ & $\begin{array}{l}\text { Mostrou à observadora como sua filha } \\
\text { ficava quando lhe dava o dedo para ela } \\
\text { segurar, a bebê estava agitada e se } \\
\text { acalmou imediatamente, fez-lhe carinho } \\
\text { e ela ficou fazendo movimentos com a } \\
\text { boca olhando para a mãe até que } \\
\text { adormeceu. Maria relatou estar } \\
\text { impressionada com o quanto sua filha } \\
\text { estava crescendo rápido e o quanto } \\
\text { estava cada vez mais esperta. No final da } \\
\text { observação, Maria foi levar a } \\
\text { observadora até o portão enquanto sua } \\
\text { filha dormia, ao chegar lá a bebê } \\
\text { começou a chorar e ela correu para } \\
\text { buscá-la, disse que toda vez que ela } \\
\text { notava a ausência da mãe chorava ou } \\
\text { ficava olhando ao redor a procurando. }\end{array}$ \\
\hline Oitava & Oito semanas & Troca de fralda & $\begin{array}{l}\text { Mostrou à observadora que quando sua } \\
\text { filha estava com dificuldade para defecar } \\
\text { ela costumava incentivar dizendo: "vai } \\
\text { filha espreme, uuuuh" e sua filha olhava } \\
\text { atentamente para a mãe e fazia o mesmo }\end{array}$ \\
\hline
\end{tabular}




\begin{tabular}{|l|l|l|}
\hline & & $\begin{array}{l}\text { barulho. Ela ficava encantada, dizendo } \\
\text { que já filmou e nem acreditava o quanto } \\
\text { a filha era esperta. Foi trocar a fralda da } \\
\text { sua filha e antes a beijou e mostrou } \\
\text { encantada as dobrinhas dela e o quanto } \\
\text { gosta de beijá-la. Relatou a dificuldade } \\
\text { de produzir leite, pensando em introjetar } \\
\text { a mamadeira. }\end{array}$ \\
\hline
\end{tabular}

Fonte: dados da própria pesquisa.

\section{IV - Discussão dos Resultados}

A relação mãe-bebê começa a ser estabelecida durante o período gestacional, por meio das expectativas que a mãe tem sobre o bebê e da interação que estabelece com ele dentro da sua barriga. Quando Maria relata, na observação 1 , sobre as expectativas dela e do marido em saber como seria o bebê fisicamente, quais características iria herdar de cada um e principalmente em relação ao sexo, houve a construção de uma imagem mental na tentativa de torná-lo familiar. Em relação ao bebê, Prado (1992) explica que, mesmo antes do nascimento do bebê, ele ocupa um papel inconsciente na vida do casal, que varia do fantasmático, imaginário (o bebê ideal) até o real, com suas exigências e características próprias. Winnicott (1994) também valoriza momentos antes do nascimento e nos diz que a função materna é necessária bem antes do nascimento do bebê, através do desejo no qual o casal insere o filho. Conforme o autor, é grande a importância do contexto do lar onde a criança vai ser gerada, a harmonia e a forma de convivência do casal são fatores que vão influenciar nas possibilidades de exercício da função materna.

No dia do parto, Maria relatou ser muito difícil descrever como estava, pois passava um turbilhão de sentimentos e que seu amor pela filha, que tinha acabado de nascer, era tão grande que dava vontade de chorar só de olhá-la. Sentiu muita angústia durante o trabalho de parto por ter medo da filha não nascer saudável ou de não conseguir amamentá-la e quando finalmente ela nasceu, e ouviu seu choro, disparou a chorar também de tanta emoção, prometendo que jamais a deixaria desamparada. Apesar da dor que sentiu devido à cirurgia e nas primeiras amamentações, descreveu como um momento único.

De acordo com Schermann (2005), é a partir do nascimento e por meio dos primeiros comportamentos interativos da mãe em relação ao bebê, e do bebê em 
relação à mãe que o vínculo afetivo entre mãe e filho é efetivamente estabelecido. Lebovici (1987) destaca a importância das primeiras horas após o nascimento do bebê para ele, pois são nelas que o elo mãecriança vai se estabelecer por meio dos primeiros comportamentos interativos da mãe em relação ao bebê, e do bebê em relação à mãe.

Nas visitas Maria relatava como estava sendo sua experiência como mãe, sobre os lugares e afazeres de que havia abdicado em prol da sua filha e como se adaptou rápido no sentido de estar sempre em alerta ao significado dos choros de sua filha e na hora da amamentação. Neste momento foi observada a capacidade que Maria demonstrou de estar atenta e identificada com sua bebê. Winnicott (1982) afirma que esta capacidade da mãe de identificar-se com seu bebê e de saber o que ele precisa, no momento em que precisa é característica do estado de preocupação materna primária, que incluiu a sensibilidade e a adaptação da mãe ao seu bebê. Afirma ainda que se a mãe for madura não ficará narcisicamente ferida por ver-se esvaziada, por um tempo, de sua vida pessoal para se dedicar a cuidar do filho. A capacidade que Maria criou em saber o significado de cada choro é devido ao vínculo que está estabelecendo com a filha e, na maioria das vezes, só a própria mãe sabe identificá-lo se é por fome, dor, sono, etc. Dessa forma, mãe e filho vão se comunicando, seja através de um choro, de um sorriso ou de um apelo por companhia.

Durante os momentos observados em que Maria ia trocar a fralda e dar banho na sua filha, presentes nas observações 1,2,3,4 e 6, era frequente ela dar sentido às expressões da filha e conversar a fim de interpretar o que a estava incomodando. Fazia perguntas junto a brincadeiras, como mexer no seu pezinho: "Nossa filha, que cheirinho é esse? Será o que temos dentro dessa fralda, hein? É um cocozinho que está incomodando? Nossa mamãe, que tanto de careta será que eu ainda quero fazer mais? Me ajuda com os gases mamãe mexe nos meus pezinhos... fummm que cocô mais fedido hein".

Segundo Oliveira (2011), para a Psicanálise, todos os bebês são prematuros, em função da dependência que eles possuem em relação a outro ser humano. $\mathrm{O}$ desamparo do bebê ao nascer é o que irá motivar uma função a ser iniciada pela pessoa que será seu cuidador, neste sentido, a função materna. De acordo com a autora, esta função faz com que a pessoa que cuidará do bebê tenha a capacidade de traduzir as manifestações orgânicas emitidas pela criança como sendo mensagens de apelo dirigidas ao adulto, que lhes irá conferir um sentido.

Winnicott (2000) traz uma importante contribuição quando descreve 
que a comunicação da mãe com seu bebê é essencialmente não-verbal, caracterizada pelo olhar e pelo contato físico, ou seja, é efetivada através de gestos, sorrisos e vocalizações. Quando a interação obtém êxito, dá oportunidade à mãe de compreender as demandas do filho, o que proporciona seu desenvolvimento físico e mental de forma sadia. Sugere que a sensibilidade da mãe para compreender os sentimentos e as necessidades do bebê é alcançada no final da gravidez e tal estado possibilita que a mãe possa identificar-se com esse bebê, adaptar-se às suas necessidades e compreender as suas demandas. $\mathrm{O}$ autor ressalta ainda que a boa evolução dos estágios posteriores do desenvolvimento depende principalmente de bons resultados nos primeiros contatos do bebê com a mãe.

Maria utilizava sempre o manhês (fala materna com entonação e prosódia específicas que são dirigidas ao bebê) para se comunicar com sua filha, demonstrando que está investindo em seu bebê, ou seja, cuida do corpo dela vendo ali um potencial sujeito e quando sua filha demonstra incômodo ela sempre procura compreender o que a mesma deseja para poder atendê-la e aos poucos vai nomeando o que acontece com ela e o que ela gosta ou não gosta. Para Winnicott(1956/1982), essas são as funções que envolvem a função materna suficientemente boa nos estágios iniciais de um bebê.

Ao comentar o pensamento de Winnicott, Zimerman (1999, p.104) afirma que "mãe suficientemente boa" é aquela que "não frustra, nem gratifica, de forma excessiva, e que possibilita um sadio crescimento do self do seu filho". A maneira que Maria via de não frustrar a filha era antecipando possíveis incômodos, como pingar colírio nos olhos da filha para não ter muita remela, pingar soríne no narizinho, passar maisena nas assaduras e cantar para ela ter um sono mais tranquilo, porém, desde o primeiro mês já foi acostumando-a com sua ausência quando ia fazer provas na faculdade, conseguindo conciliar frustrações e gratificações.

Maria nos momentos da amamentação relatava situações com sua filha que a deixavam encantada, principalmente ao perceber o quanto ela estava cada dia mais esperta. Na observação 6 , contou dos gritinhos que a filha dava quando conversava com ela, como se estivesse querendo responder à mãe. Conforme expõe Bowlby (2002), os bebês procuram estar em contato com as mães, como pôde ser visto durante as observações, através de gestos que vão além do choro, como sorrir para elas e vocalizar, fatos que permitem entender que há apego entre as díades. Para o autor, o fato de o bebê buscar manter a mãe próxima é o chamado 
comportamento de apego, e o da mãe de responder a essa demanda é descrito como comportamento de amor materno, e quando esses comportamentos ocorrem e progridem em harmonia o par estará feliz, mesmo havendo a presença de conflitos.

Winnicott (1982) ressalta que a amamentação é um exemplo importante de um dos primeiros meios de comunicação e formação de vínculo entre a mãe e seu bebê. Maria, apesar de ter dificuldades ao amamentar nos primeiros dias (observação 1), notou a importância deste momento para sua filha, porém após dois meses parou de produzir leite. Para introjetar a mamadeira (observação 2), seguia uma rotina: colocava-a para tentar mamar no seu seio e depois lhe dava a mamadeira, sempre a olhando nos olhos. Para o autor supracitado, um dos aspectos importantes da amamentação está presente também no uso da mamadeira, como, por exemplo, a troca de olhares entre a mãe e o bebê, que é um aspecto fundamental no estágio de desenvolvimento primário.

Entende-se que a família possui grande importância no desenvolvimento da criança, na observação 5 foi presenciado todos reunidos e interessados pelas atividades que eram realizadas com a bebê, Telles (2011) vai apontar sobre como essa dinâmica familiar interfere, já que é no seio familiar que o sujeito vai vivenciar seus interesses e necessidades, bem como experiência conflitos e preparar-se para adentrar e se relacionar com círculos sociais maiores.

\section{Considerações Finais}

Ao se retornar ao objetivo deste estudo - investigar como a relação mãebebê é construída nos primeiros meses de vida do bebê - pode-se afirmar que através do estudo de caso apresentado foi possível alcançar esse objetivo e possibilitou ter contado direto de como essa relação vai se estabelecendo.

O estudo de caso apontou para questões relevantes a respeito de uma relação mãe-bebê bem estabelecida, mostrando aspectos significativos como: atitudes responsivas de empatia e disponibilidade emocional que podem ser consideradas vitais para o estabelecimento de um vínculo materno saudável. Nota-se que essa relação que está se constituindo terá um papel fundamental no desenvolvimento global da criança descrita e se estenderá para a vida adulta. As reações emocionais da dupla demonstraram que, além da capacidade de renúncia da mãe, como Maria relatou diversas vezes ter abdicado de saídas e afazeres, o nascimento da sua filha a levou a repensar todo seu projeto de vida, o que conduz ao pressuposto de que nesse caso apresentado 
o desenvolvimento da díade observada tem grandes possibilidades de sucesso.

Neste trabalho, viu-se como a relação mãe-bebê é a primeira forma de socialização e tem consequências duráveis e importantes do ponto de vista social e emocional, sendo que a vinculação e o laço afetivo entre a díade é que darão segurança emocional e conforto para a criança. Dessa forma, a partir da fundamentação teórica, formulada por diferentes autores, foi possível concluir que quando um bebê recebe o cuidado afetivo adequado por parte de sua mãe tende a se constituir psiquicamente estruturado.

Pôde-se constatar que através do estudo realizado a dúvida norteadora sobre como a relação mãe-bebê é construída nos primeiros meses de vida do bebê foi respondida e não houve nenhuma situação que mudou o foco da pesquisa proposta, pois, apesar da não autorização da equipe médica em acompanhar o parto, as observações não foram prejudicadas. Porém, houve pontos que podem ser melhorados em uma continuidade dessa pesquisa, tais como ter supervisão nas observações em grupo, como propõe o método Bick, permitindo ampliar e facilitar as discussões, já que haverá novas percepções sobre os fatos e se as observações fossem durante dois anos auxiliariam em uma análise mais profunda do caso observado.

\section{Referências}

Bick, E. (1987). Child analysis today. In: Harris, M.; Bick, E. (Orgs.). Collected papers of Martha Harris and Esther Bick (pp. 104-113). Great Britain: The Roland Harris Education Trust. (texto original publicado em1961).

Bick, E. (1987). Notes on infant observation in psycho-analytic training. Em Harris, M. e Bick, E. Collected papers of Martha Harris and Esther Bick. (pp. 240-256). Great Britain: The Roland Harris Education Trust. (texto original publicado em1964)

Bowlby, J. (2002). Apego e perda - Apego: A natureza do vínculo. São Paulo: Martins Fontes. (texto original publicado em1988)

Borsa, J. C. (2007). Considerações acerca da relação mãe-bebê, da gestação ao puerpério. Contemporânea - Psicanálise e Transdisciplinaridade, Porto Alegre, (2),310-321, Abr/Mai/Jun 2007. Disponível em: www.contemporaneo.org.br/contemporanea.php. Acesso em 13 mar. 2013.

Brasil (2012), Conselho Nacional de Saúde. Resolução 466, que estabelece as normas para a realização de pesquisa com seres humanos. Diário Oficial da União, Brasília.

Brasil (2016), Conselho Nacional de Saúde. Resolução 510, que estabelece as normas para a realização de pesquisa com seres humanos. Diário Oficial da União, Brasília. 
Chizzotti, A. (2005). Pesquisa em ciências humanas e sociais. São Paulo: Cortez.

Chiadi, R. (2015). Um breve estudo sobre a posição depressiva - Melanie Klein. Publicado em 19 de August de 2015.<disponível em: http://www.webartigos.com/artigos/um-breveestudo-sobre-a-posicao-depressiva-melanie-klein/134854>. Acesso em: 20/04/2017.

Dolto, F. \& Nasio, J.D. (1991). A criança do espelho. Porto Alegre, Artes Médicas.

Farias, E. P. \& Tucherman, S. E. (1988). A observação da relação mãe-bebê e a formação analítica, Revista Brasileira de Psicanálise, 1988, 23(4), 595-609.

Freud, S. (2006a). Os instintos e suas vicissitudes. In Edição Standard Brasileira das Obras Completas de Sigmund Freud. Rio de Janeiro: Imago. v. XIV. (texto original publicado em 1915).

Freud, S. (2006b). Três ensaios sobre a teoria da sexualidade [1901-1905]. In: Obras Completas de Sigmund Freud. Rio de Janeiro: Imago. (texto original publicado em 1905).

Gil, A. C. (2008). Como elaborar projetos de pesquisa. São Paulo: Atlas.

Goode, W. \& Hatt, P. (1973). Métodos em pesquisa social. São Paulo, SP: Nacional.

Goldenberg, M. (2003). A arte de pesquisar: como fazer pesquisa qualitativa em ciências sociais. São Paulo: Record.

Klein, M. 1978). Sobre a observação do comportamento do bebê. In: Klein, Melanie e outros. Os progressos da psicanálise, (pp. 256-289). Rio de Janeiro: Zahar.

Kompinsky, E. (2000). Observação de bebês: método e sentimentos do observador In: CARON, Nara Amália (Org.). A relação pais-bebê: da observação à clínica, (pp.09-31). São Paulo: Casa do Psicólogo.

Lebovici, S. (1987). A constituição do elo entre a mãe e o recém-nascido. O bebê, a mãe e o psicanalista, (pp.115-126). Porto alegre: Artes médicas.

Oliveira. M. G. (2011). Função maternal e a constituição subjetiva na condição de prematuridade. The published masther's thesis. Programa de pós-graduação em Psicologia, Universidade Federal do Pará. Pará, Brasil.

Oliveira-Menegotto, L. M., Menezes, C. C., Caron, N. A. \& Lopes, R. C. S. (2006). O método Bick de observação de bebês como método de pesquisa. Psicol. clin. Rio de Janeiro, 18(2), 77-96. DOI.10.1590/S0103-56652006000200007

Perez-Sanchez, M. (1983). Observação de bebês: relações emocionais no primeiro ano de vida. Rio de Janeiro: Paz e Terra.

Prado, L. C. e outros (1992). Programa de observação: Bebês e sua interação com o ambiente familiar. Publicação CEAPIA. Porto Alegre, 4, 57-64. 
Piccinini, C.A., Seidl de Moura, M.L., Ribas, A.F.P, Bosa, C.A., Oliveira, E.A.F., Pinto, E.B., Schermann, L. \& Chahon, V.L. (2001). Diferentes perspectivas na análise da interação pais-bebê/criança. Psicologia, Reflexão e Crítica, 14(3),469-485. DOI.10.1590/S010279722001000300004.

Spitz, R. (1965). A. The first year of life: psychoanalytic study of normal and deviant development of object relation. New York: International Universities Press. (texto original publicado em 1945).

Telles, J. C. C. P., Sei, M. B. \& Arruda, S. L. S. 2010). Comunicação silenciosa mãe-bebê na visão winnicottiana: Reflexões teórico-clínicas. Aletheia, (33), 109-122.

Zimerman, D. E. (1999). Fundamentos psicanalíticos: Teoria, técnica e clínica. Porto Alegre: Artes Médicas.

Winnicott, D. W. (1983). Distorção do ego em termos de falso e verdadeiro "self". In: Winnicott D.W.O ambiente e os processos de maturação: estudos sobre a teoria do desenvolvimento emocional, (pp.128-139). Porto Alegre: Artes Médicas. (texto original publicado em1963).

Winnicott, D. W. (1982). Preocupação materna primária. In: D. W. Winnicott, Textos selecionados: da pediatria à psicanálise, (pp.491-498). Rio de Janeiro: Francisco Alves. (texto original publicado em 1956).

Winnicott, D.W. 1987). Os bebês e suas mães. São Paulo, Martins Fontes. (texto original publicado em 1956).

Os autores:

Juliana Carneiro de Souza, psicóloga, graduada pela Universidade Federal de Goiás, Regional Catalão, e-mail, juliana_juh_08@hotmail.com.

Moisés Fernandes Lemos, psicólogo, especialista em Filosofia, especialista em Psicologia Clínica, mestre em Psicologia Clínica, doutor em Educação, pós-doutor em saúde coletiva, professor adjunto da Universidade Federal de Goiás, Regional Catalão, e-mail: moisesflemos@ yahoo.com.br

Recebido em: 28/12/2017.

Aprovado em: 20/05/2018. 